\title{
A Relationship between Tyre Pressure and Rolling Resistance Force under Different Vehicle Speed
}

\author{
Apiwat Suyabodha \\ Department of Automotive Engineering, Rangsit University, Lak-hok, Pathumthani, Thailand
}

\begin{abstract}
Tyres are a final output torque of the vehicle before all the forces are distributed to the road surface as a tractive force. When the tyre pressure changed, it had a direct effect on rolling resistance force of the vehicle and reduced the tractive force. Moreover, it had an effect on a rate of fuel consumption and driving comfort. This research had tested the effect of tyre pressure of $25 \mathrm{psi}$ and 45 psi to determine the total resistance force between the vehicle speed from $40 \mathrm{~km} / \mathrm{hr}$ to $100 \mathrm{~km} / \mathrm{hr}$ and compare with the reference tyre pressure of 35 psi by using the "coast-down technique". The results from calculation showed the total resistance force when the vehicle speed was zero from tyre pressure of $25 \mathrm{psi}$ increased by $48.52 \%$ from reference value and the total resistance force from tyre pressure of $45 \mathrm{psi}$ decreased by $13.46 \%$ from the reference tyre pressure. The different resistance force from tyre pressure of 35 psi with the other 2 values of tyre pressure in the research were called the different rolling resistance force because the vehicle changed only tyre pressure which had no effect on aerodynamics drag. The relationship of the different rolling resistance force along the test speed from tyre pressure of $25 \mathrm{psi}$ and 45 psi decreased while the vehicle speed increased. The relationship can be fitted with a linear equation. The slope from tyre pressure of 25 psi was 0.2358 which was steeper than the slope of 0.0828 from 45 psi tyre pressure. These were the effect of tyre characteristic that made from rubber. When the vehicle speed was low, the frequency of tyre deformation was also low and resulted in high energy loss from hysteresis phenomena. Therefore high rolling resistance force was generated. Considering the effect of tyre under high vehicle speed, the frequency of tyre deformation increased and made the molecule of rubber vibrate more than low vehicle speed. These effects made the tyre stiffer than low frequency and resulted in decreasing the rolling resistance force. In additional, high frequency that caused by high tyre pressure had effected on driving comfort in a real driving condition.
\end{abstract}

\section{Introduction}

A vehicle uses an internal combustion engine as a power unit to produce a torque for pushing the vehicle body moving forward. The torque from engine is generated by pressure from burning fuel and air in the combustion chamber during power stroke $[1,2]$. Then, the pressure pushes the piston move down to the bottom dead centre. Next, the piston moves up to the top dead centre for release the exhaust gas. The process continues to draw the fuel and air in the combustion chamber and the mixture of air and fuel are compressed in the compression stroke for the next power stroke. The cycle of combustion make the piston move up and move down in the combustion chamber. The movement of piston is converted to rotation by crankshaft and generates output torque $\left(\mathrm{T}_{\text {engine }}\right)$ as can be expressed by (1)

$$
\mathrm{T}_{\text {engine }}=\mathrm{mep} \cdot \mathrm{V}_{\mathrm{d}} /\left(6.28 \cdot \mathrm{n}_{\mathrm{R}}\right)
$$

where

$$
\begin{aligned}
& \text { mep }=\text { mean effective pressure }(\mathrm{Pa}) \\
& \mathrm{V}_{\mathrm{d}}=\text { engine displacement }\left(\mathrm{m}^{3}\right) \\
& \mathrm{n}_{\mathrm{R}}=\text { number of crank revolution for each power stroke }
\end{aligned}
$$

(for 4-stroke engine is equal to 2)

Torque from the engine is transmitted to a gearbox for developing a sufficient torque for moving and accelerating the vehicle from standstill to the design speed [3]. In gearbox, there are different size of gears that are meshed in series for varying torque and the speed of vehicle as explain in (2) and (3).

$$
\begin{aligned}
& \mathrm{T}_{\text {wheel }}=\mathrm{T}_{\text {engine }} \cdot \mathrm{i}_{\text {total }} \\
& \mathrm{n}_{\text {wheel }}=\mathrm{n}_{\text {engine }} / \mathrm{i}_{\text {total }}
\end{aligned}
$$


where

$\mathrm{T}_{\text {wheel }}=$ output torque to the wheel (N.m)

$\mathrm{n}_{\text {engine }}=$ engine speed $(\mathrm{rpm})$

$\mathrm{n}_{\text {wheel }}=$ wheel speed $(\mathrm{rpm})$

$\mathrm{i}_{\text {total }}=$ total gear ratio

The output torque for moving the vehicle forward on the flat road surface needs to meet a minimum resistance force as showed in Fig 1. which is a combination between an aerodynamics drag $(\mathrm{Rd})$ and a rolling resistance force $\left(\mathrm{R}_{\mathrm{r}}\right)$ following (4) and (5) respectively [4];

$$
\begin{aligned}
& R_{d}=(1 / 2) \cdot \rho \cdot C_{d} \cdot A \cdot v^{2} \\
& R_{r}=K_{r} \cdot W
\end{aligned}
$$

where;

$$
\begin{array}{ll}
\rho & =\text { density of air }\left(\mathrm{kg} / \mathrm{m}^{3}\right) \\
\mathrm{C}_{\mathrm{d}} & =\text { coefficient of aerodynamics drag } \\
\mathrm{A} & =\text { frontal area of vehicle }\left(\mathrm{m}^{2}\right) \\
\mathrm{V} & =\text { vehicle speed }(\mathrm{m} / \mathrm{s}) \\
\mathrm{K}_{\mathrm{r}} & =\text { coefficient of rolling resistance } \\
\mathrm{W} & =\text { weight of vehicle }(\mathrm{N})
\end{array}
$$

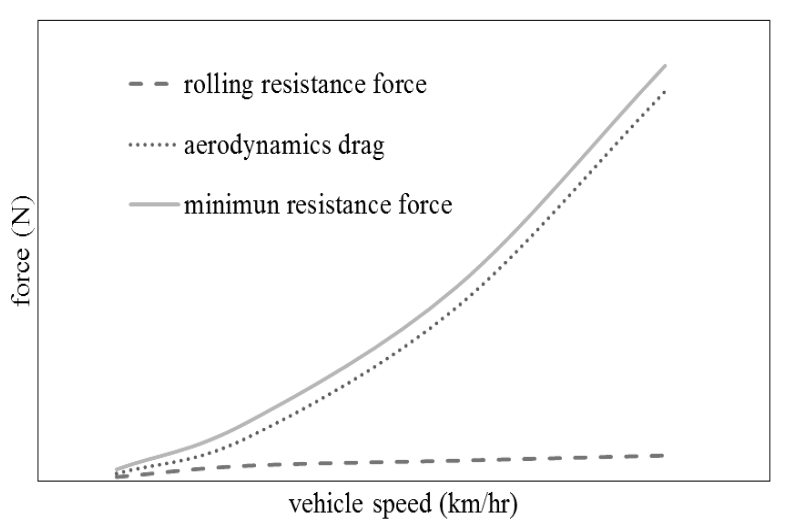

Figure 1. A minimum resistance force for driving a vehicle at constant speed which is a combination between rolling resistance force and aerodynamics drag.

Considering the rolling resistance force, it is a force that acts on the opposite of the direction of tyre motion. The rolling resistance force is not constant and mainly depends on tyre speed, tyre pressure and properties of tyre as it made from rubber. Fig 2. showed the mechanism of tyre which is rolling on the flat road surface, the front edge of tyre contact area has high stress compare to the tailing edge. These results of the total reaction force $\left(\mathrm{F}_{\mathrm{z}}\right)$ that locates in the front edge of the tyre contact area and generated counter moment in the opposite direction of the tyre motion $[5,6]$.

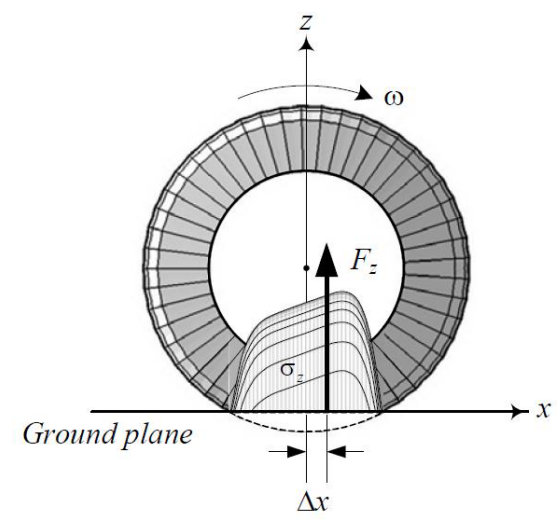

Figure 2. Side view of normal stress distribution of tyre [5]

In 1999, the research proved that the coefficiency of rolling resistance reduced while the tyre pressure increased. The relationship of both parameters was fitted with an exponential function [7]. Another research focused on measuring the friction torque of vehicle tyre and claimed the friction torque which referred to the rolling resistance force reduced while the vehicle speed increased under constant tyre pressure [8-10].

In additional, the rolling resistance force is defined as an energy loss from tyre deformation. When the tyres rotate on the road surface under loading, the contact area as showed in Fig 2. is compressed and cause tyre deformation. Under unloading condition, the tyre is uncompressed and returns to original position. Considering the energy as showed in Fig 3., the deformation force for tyre under loading condition is greater than the deformation force for unloading condition. The area in the loop is the hysteresis loss [11].

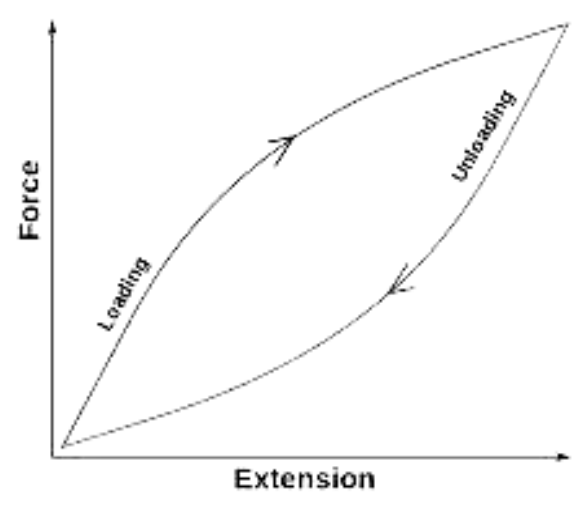

Figure 3. Hysteresis Loop of tyre [11]

Low tyre pressure has hysteresis loss more than high tyre pressure because the tyre has high deformation. The relationship of hysteresis loss proved that the loss gradually reduced when the tyre pressure increased [12]. Moreover, low tyre pressure had low tyre stiffness because the molecule of rubber vibrates more than high tyre pressure [13]. The stiffness increased as a linear 
function with the tyre pressure [12]. In the other word, low hysteresis loss means low rolling resistance force which results in increasing the vehicle power but the tyre is very stiff so it has an effect on driving comfort.

\section{Aim of research}

The research is aimed to study the effect of tyre pressure on the rolling resistance force by comparing with the tyre pressure that giving by the automotive manufacturing as a reference value. The coast-down technique had been used to determine the resistance force of the vehicle. The research also narrowed down to the result and discussion on the force of different tyre pressure under the same vehicle speed which is difference from the previous research.

\section{Coast - down technique}

The test in this research was carried out by using "coastdown technique" [14]. The basic principle of this technique is to accelerate the vehicle on the flat road to a predetermined speed and let the vehicle decelerate in neutral gear down to the predetermined speed and record the time during decreasing speed. The total resistance force (Ftotal) is calculated from Newton's second law by using the vehicle weight and the different speed and time according (6)

$$
\mathrm{F}_{\text {total }}=\mathrm{m} \cdot \Delta \mathrm{v} / \Delta \mathrm{t}
$$

where;

$$
\begin{array}{ll}
\mathrm{m} & =\text { weight of vehicle }(\mathrm{kg}) \\
\mathrm{v} & =\text { vehicle speed }(\mathrm{m} / \mathrm{s}) \\
\mathrm{t} & =\text { time }(\mathrm{s})
\end{array}
$$

This technique is used for estimation the total resistance force which is the aerodynamics drag and the rolling resistance force. This research applied the technique for estimation the rolling resistance force. As the vehicle was the same condition, the tyre pressures were the only factor that was changed. Therefore the different resistance force from tyre pressure were claimed to be the changing of rolling resistance forces by this technique.

\section{Methodology}

The research used the pick-up truck vehicle that had front engine with 2500 c.c. included turbocharged system. The transmission was a real wheel drive with a manual gearbox. The engine had 4 cylinders with water cooled system. The total weight of vehicle was 1560 kilograms. The size of tyre was 215/70 R15.

The test condition used the flat road surface which made from asphalt. The test was carried out when the speed of atmosphere wind was zero in order to avoid the extra force from aerodynamics drag. The test procedure was;

1) Set up the tyre pressure to 25 psi for all 4 tyres. Start the engine and run the vehicle until the speed achieved $110 \mathrm{~km} / \mathrm{hr}$ and then disengaged the gearbox from engine by put the gear to neutral position and let the vehicle slow down by itself. Start to record the time when the speed of vehicle was $100 \mathrm{~km} / \mathrm{hr}$ and recorded the time every changing speed of $5 \mathrm{~km} / \mathrm{hr}$ until the vehicle speed slow down to $40 \mathrm{~km} / \mathrm{hr}$.

2) Repeat the test by changing the tyre pressure to 35 psi according to the vehicle manufacturing and 45 psi respectively.

\section{Results and discussions}

According to the coast-down test, the vehicle speed decreased very fast with the tyre pressure of 25 psi but under the tyre pressure of $45 \mathrm{psi}$, the vehicle speed decreased slightly slower than 35 psi trye pressure. The relationships between time and vehicle speeds were plotted and were fitted with exponential equations as shows in Fig 4.

The time for decreasing the vehicle speed from 100 $\mathrm{km} / \mathrm{hr}$ to $40 \mathrm{~km} / \mathrm{hr}$ with the tyre pressure of $25 \mathrm{psi}, 35 \mathrm{psi}$ and 45 psi were 58.90 seconds, 78.69 seconds and 85.57 seconds respectively. For more analysis, the results in Fig 4 had been converted to the total resistance force and fitted with the exponential equations as can be seen from Fig 5.

The exponential equations showed the value of resistance forces which were the combination between aerodynamics drag and rolling resistance force at different vehicle speed. When the vehicle speed was zero, the line of relationship crossed the total resistance force axis which represented only the rolling resistance force of the tyre. With zero vehicle speed, the value of rolling resistance force from 35 psi tyre pressure was $86.489 \mathrm{~N}$. Under the tyre pressure of $25 \mathrm{psi}$, the exponential showed the results of the rolling resistance force increased by $48.52 \%$ while the rolling resistance force from tyre pressure of 45 psi decreased by $13.46 \%$. Considering the different resistance force by using the 35 psi as a reference value of tyre pressure from the vehicle speed of $40 \mathrm{~km} / \mathrm{hr}$ to $100 \mathrm{~km} / \mathrm{hr}$ in Fig 6 . The different values represented the only changing in rolling resistance force for each vehicle speed because changing tyre pressure had no effect on aerodynamics drag. 


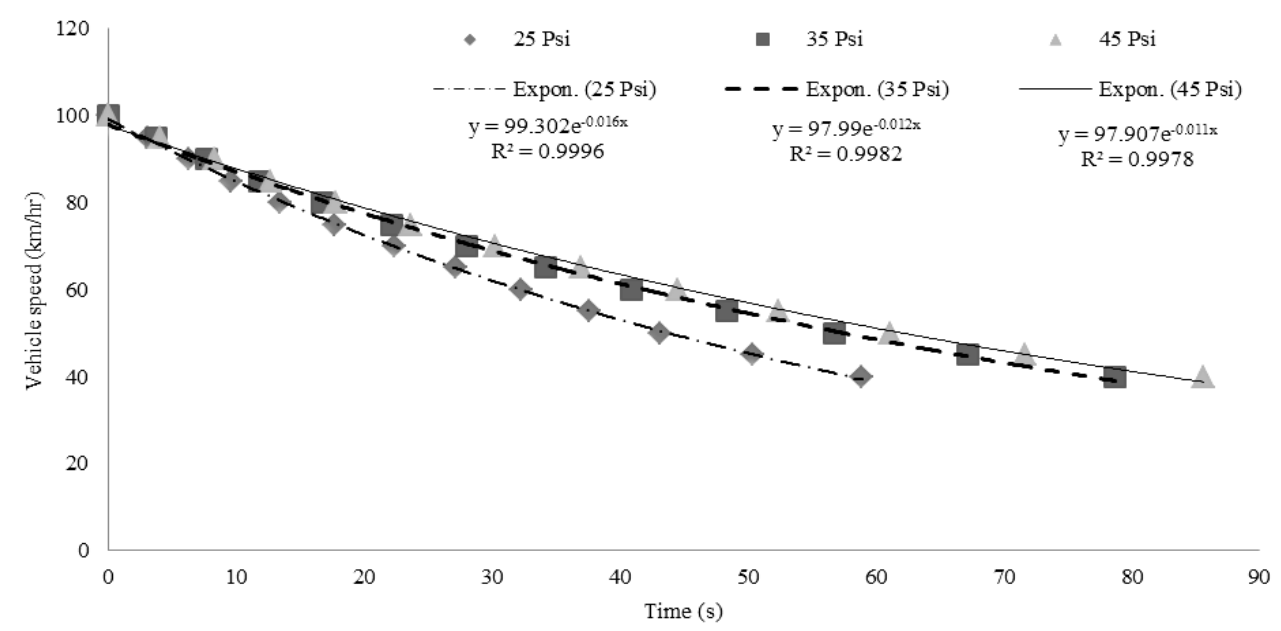

Figure 4. A relationship between time and vehicle speed under different tyre pressure.

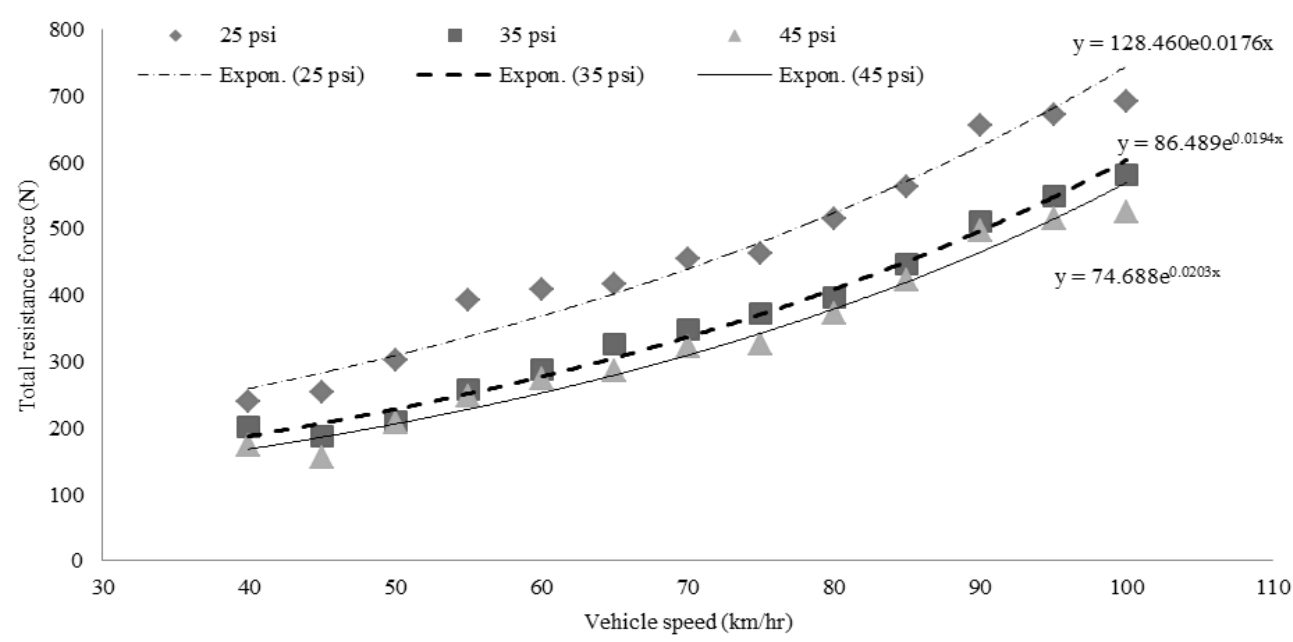

Figure 5. A relationship between vehicle speed and total resistance force under different tyre pressure.

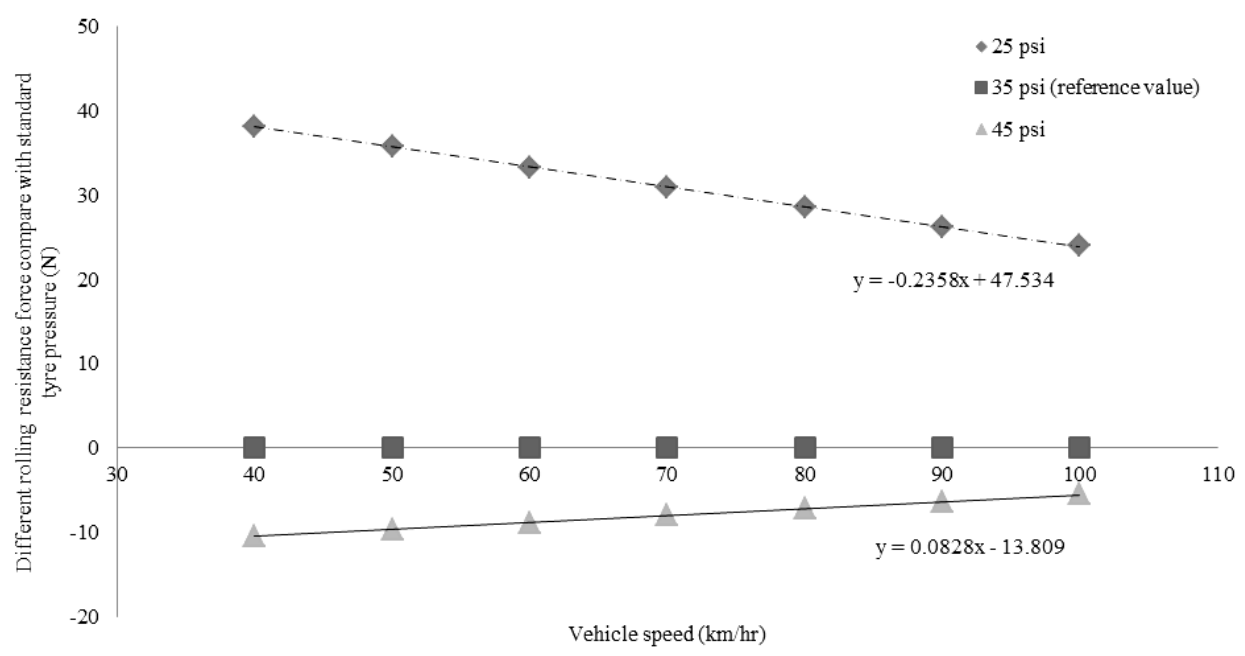

Figure 6. The different resistance force compare to the resistance force from reference tyre pressure of $35 \mathrm{psi}$ 
The different resistance force of the trye pressure of 25 psi and 45 psi in Fig 6. were fitted with linear equations while the tyre pressure of 35 psi was used as a reference value. Under 25 psi of tyre pressure, the rolling resistance force decreasing with the slop of 0.2358 while the slope of 45 psi tyre pressure was only 0.0828 . This phenomenon was the effect of tyre properties and the rate of tyre deformation. Under low vehicle speed, the rate of tyre deformation was high which increased hysteresis loss and resulted in high rolling resistance force. When the vehicle speed increase, the molecules of tyre moving faster than low speed which made the tyre stiffer than low vehicle speed. In additional, high tyre stiffness results in low hysteresis loss. These physical phenomenon had high effect on 25 psi of tyre pressure but under trye pressure of 45 psi, the tyre was already stiffer than the other pressure. The results also proved that the stiffness of the tyre increased with the vehicle speed.

\section{Conclusion}

This research was focused on the effect of tyre pressure and rolling resistance force. The coast-down technique was used to determine the resistance force of vehicle under tyre pressure of 25 psi and 45 psi by comparing with the reference tyre pressure of 35 psi which was set from the vehicle manufacturing. The results showed the rolling resistance force increased $48.52 \%$ when the pressure of tyre was 25 psi. Under tyre pressure of $45 \mathrm{psi}$, the rolling resistance force reduced $13.46 \%$ from the reference value. These results proved the low tyre pressure made the tyre deformed more than the high tyre pressure during rotating on the flat road surface and caused high hysteresis loss. However, the value of rolling resistance force reduced when the vehicle speed increased because the tyre contacted the road surface in a short period of time. Therefore, the frequency of tyre that contacted on the road surface was high and caused the molecule of the rubber tyre moved faster than low vehicle speed. This phenomenon made the tyre stiffer than low vehicle speed and made the value of rolling resistance force reduced. Considering the hysteresis phenomena, the deformation of tyre under high vehicle speed was less than low vehicle speed. Therofore, the energy loss from hysteresis phenomena was low and allowed more output torque to be transmitted to the road.

\section{Future works}

According to this research, the relationship of rolling resistance force and tyre pressure were explained. For the future test on this research, the tyre pressure of $25 \mathrm{psi}, 35$ [15] psi and 45 psi are used for conducting the test on acceleration rate and fuel consumption rate. The results are used to explain an effect of different tyre pressure under real driving condition which would be benefit for daily use.

\section{Acknowledgment}

I would like to acknowledge Rangsit University for supported some fund for conducting this research. Also, I would like to thanks Damrong Limsomporn for helping me to conduct the test and collected the data.

\section{References}

[1] J.B. Heywood, "Internal Combustion Engine Fundamentals", International Edition, McGraw-Hill Book Company (1988)

[2] R.Stone, "Introduction to Internal Combustion Engines", $3^{\text {rd }}$ Society of Automotive Engineers, Inc (1999)

[3] H. Heisler, "Vehicle and Engine Technology", $2^{\text {nd }}$, ButterworthHeinemann (1999)

[4] Robert Fischer R., Küçükay F., Gunter Jürgens G., Najork R. and Pollak B., "The Automotive Transmission Book", Springer International Publishing Switzerland (2015)

[5] R.N. Jazar, "Vehicle Dynamics : Theory and Appication", Springer Science+Business Media, LLC (2008)

[6] J. Reimpell, H. Stoll and J.W. Betzler, "The Automotive Chassis : Engineering Principles", Ed 2 ${ }^{\text {nd }}$,Butterworth-Heinemann (2001)

[7] F. Grappe, R. Candau, B. Barbier, M.D. Hoffman, A. Belli and J.D. Rouillon, "Influence of tyre pressure and vertical load on coefficient of rolling resistance and simulated cycling performance", Ergonomics, Vol 10, page 1361-1371 (1999)

[8] Pedro de F.V. Carvalheira, "An Experimental Method to Measure The Tire Rolling Resistance Coefficient of An Ultra-Efficient Vehicle", $15^{\text {th }}$ International Conference on Experimental Mechanics, 22-27 July (2012)

[9] V.V. Mozharovskii, S.V. Shilko, S.B. Anfinogenov and A. V. Khotko, "Determination of resistance to rolling of tires in dependence on operating conditions. part 1. method of multifactorial experiment", Journal of Friction and Wear, Vol 28, page 154-161 (2007)

[10] J.C. Páscoa, F.P. Brójo, F.C. Santos and P.O. Fael, "An innovative experimental on-road testing method and its demonstration on a prototype vehicle", Journal of Mechanical Science and Technology, Vol 26, page1663 - 1670 (2012)

[11] D. Mukherjee, "Effect of Pavement Conditions on Rolling Resistance", American Journal of Engineering Research (AJER), Vol 3, Issue 7, page 141-148 (2014)

[12] P.S. Pillai, "Inflation pressure effect on whole tyre hysteresis ratio and radial spring constant", Indian Journal of Engineering \& Materials Sciences, Vol 13, page 110-116 (2006)

[13] P. Haney, "The Racing \& High-Performance Tire", TV Motorsports abd SAE (2003)

[14] P. Norrby, "Prediction of coast-down test results : A statistical study of environmental influences", Master of Science Thesis, Chalmers University of Technology (2012) 